\title{
Chapter 12 \\ Knowledge and the Deliberative Stance in Democratic Systems: Harnessing Scepticism of the Self in Governing Global Environmental Change
}

\author{
Simon Niemeyer
}

Deliberative democracy is characterized as an approach to governance that valorizes the operation of reason (Chambers, 2012; Cohen, 2007). Although there is a danger of this interpretation implying hyper-rationalism, as some researchers have suggested, considerable scope exists for understanding the relationship between knowledge, reason, and governance in a broader sense using a deliberative lens (see Bächtiger, Niemeyer, Neblo, Steenbergen, \& Steiner, 2010). To begin, the emphasis on deliberation implies that the mere fact of knowledge is insufficient to derive legitimacy for any particular action. An actor may use knowledge to demonstrate the existence of climate change, for example, but the choice of what action to take involves normative questions about what the polity values, which can only be addressed with reference to citizens.

At the same time, the relationship between citizens, knowledge, and collective choices is not improving, and may possibly even be deteriorating (Capstick, Whitmarsh, Poortinga, Pidgeon, \& Upham, 2015). The problem is not ignorance per se, nor a lack of baseline will (O'Brien, 2012). When surveyed, most citizens endorse environmental sustainability, but the message is often lost in political translation. However, it is important to understand the broader dynamics of knowledge, and the processes whereby these are translated into action. Take for example the "governance trap," where basic acceptance of the fact of climate change fails to translate into action, because citizens and the government each attribute responsibility for such action to the other, thus ossifying inaction (Pidgeon, 2012). In this chapter, I seek to develop an understanding of these processes through a deliberative framework.

To this end, I begin the chapter with a survey of the challenge of translating knowledge into political action, demonstrating how a governance lens, particularly

\footnotetext{
S. Niemeyer $(\bowtie)$

Centre for Deliberative Democracy and Global Governance, University of Canberra,

Canberra, ACT, Australia

e-mail: simon.niemeyer@ canberra.edu.au
}

J. Glückler et al. (eds.), Knowledge for Governance, Knowledge and Space 15, 
a deliberative one, can illuminate these dynamics. I then illustrate them using a case study that compares the effect of knowledge gains of climate impacts to the absence or presence of deliberation, via relative changes to discourses of climate change governance. I argue that an important feature influencing the impact is not just the role of knowledge, but also the changing disposition of citizens, which is impacted by the deliberative context. I examine this dispositional effect using the concept of the deliberative stance, then develop these findings into broad possibilities for improving the relationship between knowledge and governance in deliberative systems, before revisiting the overall findings in a concluding section.

\section{Knowledge and Governance Systems in Climate Change}

Researchers have known the basic science underpinning anthropogenic climate change since the latter part of the nineteenth century. Originally heavily contested, the scientific consensus has moved on from debating its existence to yielding increasingly alarming revisions of earlier findings in respect to its pace and impacts (Oreskes, 2018).

Yet, despite the growing evidence there is a growing gap between the scale of the problem and the need for action that it implies (e.g., Dunlap, 2013). Self-interest at the national level is part of the problem, particularly where politics is dominated by the fossil fuel and associated industries (e.g., Christoff, 2013), but this is only part of the picture. In any system of governance there remains a thread of legitimization between the public and decision makers responding to (or at least managing) popular demand for action on climate change. The problem remains that this level of demand has varied considerably over time, even declining in some countries (Capstick et al., 2015).

Although a liberal view might support the right of citizens to choose as they wish, a deliberative democratic view of governance demands that such a deficit be understood. If it reflects a systematic dislocation between generalizable public interest (such as maintaining a healthy environment; see Dryzek, 1990) and expressed preferences, remedies must be sought to realign the two.

In recent history, researchers have viewed these dynamics through an information deficit prism, whose proponents hold that the public, once appraised of the climate change risk, will follow suit and demand action. To be sure, climate change knowledge is correlated to action (Bord, O'Connor, \& Fischer, 2000), and there exists a knowledge deficit in relation to climate change among members, evidenced for example by a tendency to conflate localized air pollution, chlorofluorocarbons (CFCs), and ozone depletion as drivers of climate change (Capstick et al., 2015). However, this relationship does not contribute very much to understanding the overall picture.

Closer inspection of knowledge dynamics through the lens of governance suggests a richer dynamic. For a start, knowledge itself is limited. Definitive knowledge in respect to climate change is increasingly unobtainable, given the complexities of the issue. Acquiring knowledge in respect to climate change concerns the degree of specialization required to understand all its extant dimensions-to a point where it 
is impossible for any given individual to be fully conversant. This complexity leads to the problem of the knowledge-ignorance paradox, in which the need for specialization induces ignorance even among experts. Among citizens, it also serves to remove knowledge ever further and decrease inclination to engage with complex issues such as climate change. Its complexity, in combination with a lack of easily communicable metaphors to translate it into a "hot" issue, makes it difficult to hold public attention (Ungar, 2000).

Consequently, governance systems require knowledge specialization, which is predicated on trust, but this increased knowledge paradoxically has the potential to undermine this trust. The greater demands on collective knowledge for complex issues such as climate change confront a countervailing need for cognitive closure-closing the mind to information inconsistent with prior beliefs (Kruglanski \& Boyatzi, 2012) - that is driven by greater demands on citizens' limited time and cognitive resources. Even the most knowledgeable citizen-including climate scientists-will need to resort to trust in the wider knowledge system in which they are situated. Many citizens appear to do just that: They accept the scientific consensus in respect of anthropogenic climate impact and support action even if they do not individually possess detailed knowledge (van der Linden, Leiserowitz, Feinberg, \& Maibach, 2015). Where the message's implications diverge from prior beliefs, however, there is a danger of ever-increasing complexity driving a wedge between the scientist and the citizen - that is, in the absence of creating a deliberative context.

Even so, the overall relationship between knowledge and behavior is complex and mediated by a range of factors, including worldview, norms (social and personal), intentions, and habits. ${ }^{1}$ Knowledge, in the form of belief in the human causes and consequences of climate change, appears to be a requisite (Bord et al., 2000) but not a sufficient condition for action, which also requires acceptance of responsibility for action (Capstick et al., 2015). Ever more sophisticated models to predict environmental behavior (Klöckner, 2013) still only account for a small proportion of variation in actual behavior, and, even if accurate, inform remedies that are piecemeal at best (Shove, 2010).

A key contention here-which suggests both a diagnosis and a cure-is that these relationships, between knowledge and behavior, are at least partly constructed by the governance context in which such behaviors occur, as well as being part of the processes that form that context. One example of this context shaping the role of knowledge is that of the prevailing ideological setting (e.g., McCright, Dunlap, \& Marquart-Pyatt, 2016). Researchers well understand the role of worldview and ideology in determining views on climate change, and they can be powerful forces that influence the views of scientists themselves within knowledge systems (e.g., Carlton, Perry-Hill, Huber, \& Prokopy, 2015).

These forces also play a role in attempts to reconstruct politics in ways that either support or work against the uptake of knowledge in political systems. McCright and

\footnotetext{
${ }^{1}$ The knowledge dimension in environmental psychology models predicting behavior tends to follow the form of awareness about the consequences associated with action, and awareness of individual responsibility for that action. For a review, see Klöckner (2013).
} 
Dunlap (2010), for example, have described an ideologically driven attempt to work against the ideal of reflexive modernism (Beck, 1992) and critical self-evaluation and confrontation of the consequences of human actions on the environment via the centrality of impact science-as opposed to production science focused on economic output — and social movements. Many of these strategies involve attacking the institutions as part of the machinery of reflexivity, as well as framing decision choices to induce "non-decisions" that maintain a status quo more consistent with their interests. This includes strategies modeled on casting enough doubt on the science of climate change to forestall public mobilization (Oreskes \& Conway, 2010; see also Chap. 3 by Scott).

Reflexive modernists advocate remedies for the problem of knowledge distorting practices in political systems such as those used by "merchants of doubt" (Oreskes \& Conway, 2010) at the macro-institutional level via the privileging of impact science and advocacy by interest groups (e.g., McCright \& Dunlap, 2010). The approach is aimed at government: balancing the impact of knowledge against unreflexive forces that often seek to maintain an advantageous status quo. However, the effectiveness is limited to the extent that it fails to engage with the effect of these processes on citizens, delegitimizing a reflexive approach just enough to maintain the status quo.

\section{Deliberative Democracy: Reflexive Systems, Reflexive Citizens}

Deliberative democracy offers a different frame from which to view the uptake of knowledge in governance systems, as well as how that process might be improved. It implies an approach to governance that engages citizens in a manner that encourages political discourse and reflection of a deliberative quality, that such a process should be broadly inclusive, and that the considered will of citizens find a mechanism inducing consequences for both specific decisions and the operation of the system of governance as a whole (Dryzek, 2009).

Deliberative democrats speak of a relationship between reflexive and deliberative modes of governance at the wider "systems" level (e.g., Dryzek \& Pickering, 2017; Stevenson \& Dryzek, 2012), but it is also important to think of how citizens function as part of these systems, and how individual-level dispositions impact on larger scale dynamics (Owen \& Smith, 2015). Habermas (2006, p. 418), for example, draws this link when he refers to the reflexive character of the public sphere as a function of how all citizens "can revisit perceived public opinions and respond to them after reconsideration."

Less developed than theories of deliberative democracy, however, are well constructed and practical mechanisms for understanding the knowledge-action dynamics among citizens. Researchers face the challenge of empirically capturing the nature of these dynamics and translating them into mechanisms for boosting the reflexivity of the system in ways that account for both systems level and citizen level processes. 
A relevant consideration involves what actual features of deliberation yield the hypothesized benefits. Although deliberative democracy researchers have tended to focus on the quality of deliberation as a process (Bächtiger et al., 2010) and the ideal features that it embodies_-such as openness, sincerity, respect, reciprocity, and intersubjectivity - there is a growing interest in how deliberation is experienced by citizens and in the demands that it makes of them.

Deliberation cannot be divorced from a set of (reflexive) capabilities that are implicit in deliberative theory via characteristics such as open-mindedness. Owen and Smith (2015) have described something akin to the activation of these capabilities when they advance the idea of a "deliberative stance":

Part of the political ideal of deliberative democracy is that its (normative) stability is generated by citizens being able intelligibly to conceive of (adopt a stance towards) themselves as equals engaged in a process of public reasoning oriented to a shared practical judgment, where such a process involves citizens reflectively taking up each other's standpoints. (p. 219)

The ideal of the deliberative stance reflects a predilection for truth seeking and contestation (Curato, Niemeyer, \& Dryzek., 2013), an openness to arguments, and a capacity for empathy (Morrell, 2010), taking seriously alternative arguments while simultaneously treating them with judicious scepticism (Kruglanski \& Boyatzi, 2012). It implies Socratic humility, an open-mindedness that continually resists the need for cognitive closure, inviting ongoing negotiation of the relationship between the self and knowledge and its integration into thought.

\section{Knowledge, Information, and Deliberation: A Case Study}

One factor that improves the uptake and integration of knowledge is that of context (Kruglanski \& Webster, 1996), including the governance setting in which politically relevant knowledge is acquired (e.g., Pierce, Lovrich, \& Dalton, 2000).

Although the term "context" can cover a multitude of possibilities (see e.g., Shove, 2010), here the governance context is primarily viewed through a discursive lens, in which the public sphere, which is a product of discourses reproduced among individuals as discursive sites, where discourses are broadly understood in similar terms to Dryzek and Niemeyer (2008, p. 481) as "a set of categories and concepts embodying specific assumptions, judgments, contentions, dispositions, and capabilities." Discourses enable the mind to process sensory inputs into coherent accounts, which can then be shared intersubjectively.

This definition of discourse provides a clue to their capacity to shape the dynamics of knowledge uptake in a governance context as well as shaping that context. These dynamics can be demonstrated via an Australian study on public responses to climate change and governance in the Australian Capital Region (from here on, the ACR study; see Hobson \& Niemeyer, 2011). The study involved investigating discourses around the question of climate change, adaptation, and governance and the relative impact of exposure to climate change scenarios and participation in a deliberative process. 
The empirical approach—described in detail in Hobson and Niemeyer (2011)— involved surveying responses to 33 statements covering themes dealing with beliefs about climate change, trust in knowledge sources, beliefs about the capacity of the system of governance to respond to the challenge, and demands about what should be done to improve that capacity (see Table 12.3 in the Appendix).

Researchers recorded two kinds of responses. The first, non-discursive, approach involved a standard Likert-scale response to the statements, from "strongly disagree" to "strongly agree" on an 11-point scale $(-5,5)$, permitting a broad analysis of aggregate changes. The second, discursive approach, required participants to sort/rank statements into a quasi-normal distribution across the same scale for analysis based on Q methodology to identify the climate governance discourses reported below.

The survey responses were recorded at the following four stages: ${ }^{2}$

Stage 1: Baseline survey before exposure to the climate change scenario;

Stage 2: Following exposure to the High Emissions climate change scenario;

Stage 3: Prior to participation in a three-day deliberative process on climate change adaptation and policy, 3 months after the climate change scenario interviews; and Stage 4: Immediately following deliberation.

Following the surveying of baseline perspectives (Stage 1), participants in Stage 2 experienced modelled climate impacts for the region as part of an extended, individual interview process. The researchers communicated the scenario via a series of PowerPoint slides illustrating modelled climate impacts associated with a "high emissions" scenario in the years 2050 and $2100 .{ }^{3}$ Participants were asked to reflect on their real-world reaction to exposure to the scenario and to re-perform the surveys.

Stage 3 involved re-performing the surveys months following the scenario interview, immediately prior to participation in a three-day deliberative process. The process began with group activities designed to activate norms consistent with the deliberative stance, followed by 2 days of presentations from witnesses speaking to a wide range of issues associated with climate change and group discussion (see Hobson \& Niemeyer, 2011). The final day involved group deliberation developing policy recommendations dealing with climate change and adaption, which was followed by the post-deliberative survey (Stage 4). The scenario phase of the study

\footnotetext{
${ }^{2}$ An additional stage was included in the original study involving exposure to a "medium" emissions climate change scenario, but is not reported here (Hobson \& Niemeyer, 2011).

${ }^{3}$ The scenarios were developed using the Commonwealth Scientific and Industrial Research Organisation's (CSIRO) OzClim model, which contains patterns of regional changes in climate projected from 23 global climate models run by and other research centres and archived at the Program for Climate Model Diagnosis and Intercomparison (PCMDI). The model enables users to select from six SRES scenarios (taken from the 'Special Report on Emissions') and two commonly used $\mathrm{CO}_{2}$ concentration stabilisation scenarios to generate projections for any of the available global climate models (Năkićenović et al., 2000). An additional "medium emissions" scenario was included in the study, but not reported here.
} 
collected viable data from 103 participants, 34 of whom-out of the 40 selectedwent on to complete the deliberative process (Stages 3 and 4).

The list of statements used for the Q-study component of the survey can be found in the appendix's Table 12.3. As per Q method, these were drawn from a database of real language statements pertaining to relevant dimensions of climate change and adaptation discourses in the public sphere (Hobson \& Niemeyer, 2011). An abridged selection of these most relevant for the discussion here is shown in Table 12.1 below.

The average responses to the statements using the first (Likert) method are shown in the four columns to the right of the statements for each stage of the study, for the subset of deliberative participants. Results for the larger set of participants in the scenario study are shown in square brackets. The significance of change for each result compared to the baseline is indicated by an asterisk, with an additional column showing the significance of change for the deliberative phase (Stages 3-4).

Table 12.1 contains significant and dramatic changes in relation to beliefs following exposure to the climate change scenarios (statements 1,3, and 25) and increased trust in scientific knowledge (6), but a decrease in information from the media (12). There was no change in belief regarding the quality of overall governance response to the issue (2), but an increased tendency to outsource this issue and to lay blame at the feet of government (33), rather than seek a broader response within the community. As will be seen below, it makes sense that there is no increase in the already high demand for education in climate change, particularly as it was understood by those most in favor of it at the baseline stage (climate sceptics, see below). This contrasts to the increasing demand that the government take responsibility (32).

The average responses in Table 12.1 for Stage 3 (3-month follow-up, prior to participation in the deliberative process) reveal that in most cases the effect of information is not sustained, as I further discuss below The standout exception to this trend is declining trust in information from the government (7) and, to a lesser extent, the media (12) —although in this case, as for the other changes at this stage, the effect is a residual from changes that occur in the scenario stage.

Deliberation, by contrast, had a qualitatively different impact. Some dramatic changes occurred, the most significant being the belief that there will be positive response to climate change (2) and demand for more educational programs (4). Beliefs about the reality of climate change grew during deliberation $(1,3$, and 25 ; although the latter two deliberative changes fell just short of achieving significance). And, although participants did not complete a follow-up survey after participation in deliberation, a number did participate in meetings 6 months after the event, as well as a number of semi-structured interviews during which most reported the enduring nature of the views formed during deliberation. This included a belief that climate change is real and problematic, despite a recent break occurring to a longterm drought (Hobson \& Niemeyer, 2011).

For almost every survey item in Table 12.1, the observed effect from the scenario stage (information effect) among the deliberative cohort is similar to the group as a whole, except in the case of Item 8 (need for strong political leadership). However, there is an overall trend of more conservative results among the wider group, likely 
Table 12.1 Statement responses—-knowledge, trust, governance (Likert Scale)

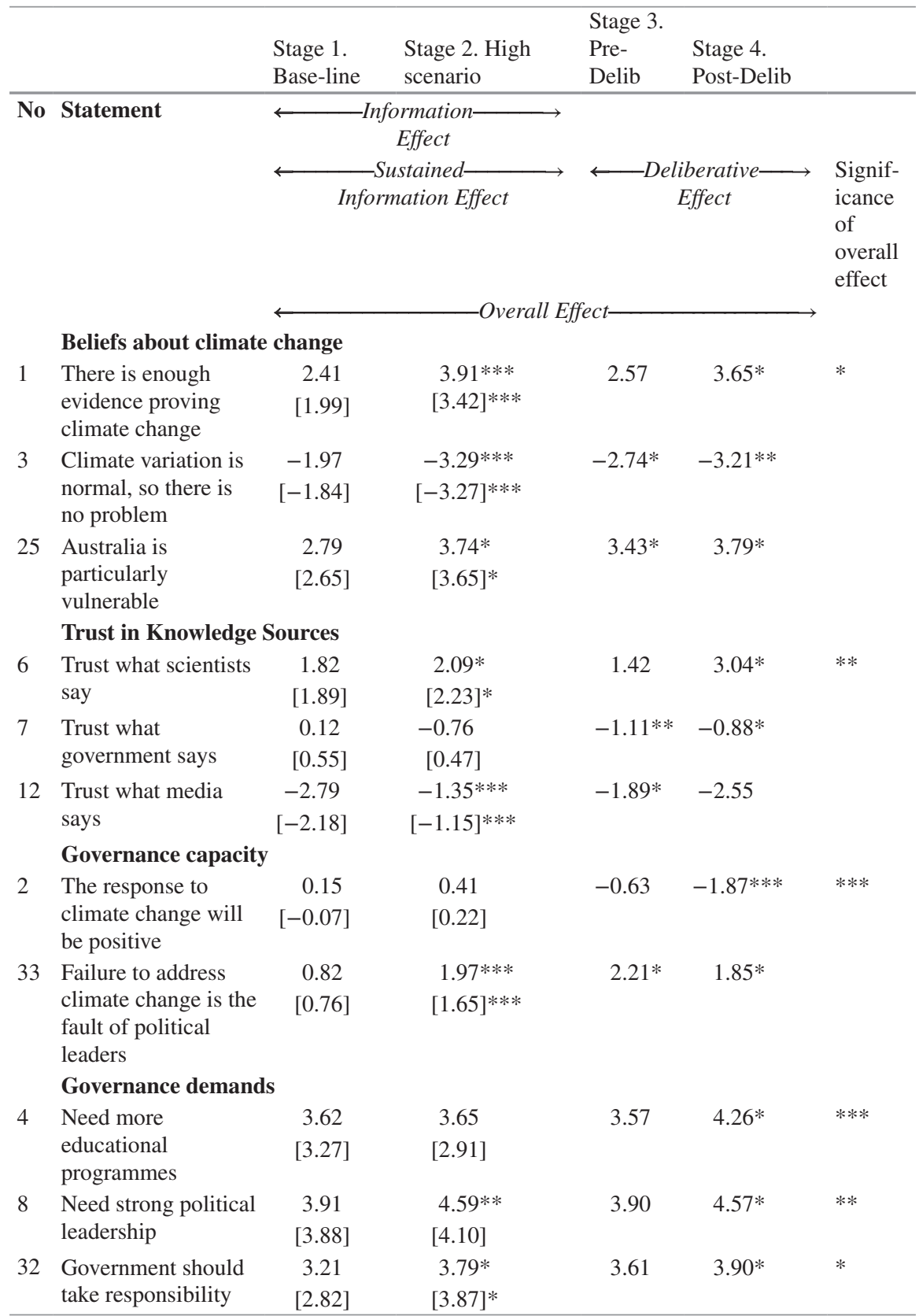

Note. Source: Design by author. Figures show the average response for that stage

Significance levels indicate the significance of change compared to the previous stage (apart from overall change indicated in the RHS column) based on T-scores where $\mathrm{H}_{0}$ : no change in average response; $\mathrm{p}<0.05^{*}, \mathrm{p}<0.01^{* *}, \mathrm{p}<0.001^{* * *}$ 
due to self-selection bias-something also observed in relation to other studies (e.g., Curato \& Niemeyer, 2013; see also Jennstål, 2018)—where a particular type of usually conservative and deep climate sceptic participant withdraws after agreeing to participate in deliberation. I will revisit this issue, and the implications for the overall findings, below.

\section{Discursive Transformation}

The ability to identify relevant "types" of individual, such as the deliberative-shy deep sceptics, was facilitated by a second type of analysis, using the forced distribution scores, based on Q methodology (Brown, 1980). This $Q$ analysis helped to discern different themes in the responses to statements among participants-called factors; although here I use the term "discourses" in an informal sense (see Dryzek, 1990). The approach is more consistent with the "sense-making" approach of discursive psychology (Niemeyer, 2019) —although there are limits to this interpretation of the method (Danielson, 2015)—where the associations between items emerge as part of the analysis, rather than a priori.

The analysis, which is described in detail in Hobson and Niemeyer (2011), resulted in four discourses, reflecting different levels of agreement/disagreement with the entire set of 33 statements, within which the positions of most participants could be located:
A. Government Scepticism
B. Government Imperative
C. Pragmatism
D. Alarmed Defeatism

I report the "typical" responses to the statements, which are used to interpret the discourses, in Table 12.3 in the appendix. In order to more easily communicate the features of each discourse - and later locate participants within them-I have located abridged versions of the survey statements schematically in Fig. 12.1 among the four overlapping discourse spheres. The statements paraphrased in Table 12.1 are shown in bold.

Discourse A represented a particular form of climate scepticism-where a dedicated analysis revealed a number of variations (Hobson \& Niemeyer, 2013)—with much lower levels of trust in knowledge sources (scientists, government, media) compared to the other discourses. Individuals associated with this discourse tended to believe climate change is an important issue-as did those in all the discourses. However, the risk is overstated for this cohort, who tended to ascribe climate change to natural climate variation. ${ }^{4}$

\footnotetext{
${ }^{4}$ The study included a large proportion of climate sceptics, a number of who held deeply sceptical positions that could not easily incorporated into the main discourse analysis and do not quite fit
} 


\section{A: Government Scepticism}

$\mathrm{CC}$ is not here (yet)

Distrust government

Distrust media

Need educational programmes

Changes could be normal

We can adapt

Need strong leadership

Up to government to act

The market won't fix the problem

Trust Scientists

$\mathrm{CC}$ is a major issue

Not simply climate variation

There is enough evidence of CC

Distrust media

Response wil NOT be positive

Unilateral action is pointless (personally or nationally)

Technology will help

\section{C: Pragmatism}

Fig. 12.1 Discourses of climate change adaptation and governance. Source: Design by author

Proponents of Discourse B are much more concerned about climate change, with greater levels of trust in scientific knowledge. But there is a strong element of displeasure in the government's response to the issue, emphasizing centralized action in ways that may not ultimately prove particularly adaptive in the absence of additional recognition of individual responsibility (Hobson \& Niemeyer, 2013)—which is consistent with social psychological models used to predict pro-environmental behavior (Klöckner, 2013).

Discourse C, although a very small discourse in terms of influence among participants, represents a pragmatist view whose proponents are optimistic that solutions can be found without causing too much disruption. Discourse D, by contrast, is entirely maladaptive, representing a retreat from any form of cooperative attempt to govern in manner that improves the collective response (see Hobson \& Niemeyer, 2011). This is not due to a lack of knowledge, but to acceptance that dramatic change is occurring.

The study's participants can be located schematically on the discourse mapusing their factor loadings, indicating how strongly they correlate to the standard responses to the survey statements represented by the discourse (see Hobson \& Niemeyer, 2011). The baseline (and high emissions) locations are indicated by the

into Discourse A. A separate analysis was conducted separately for the entire climate sceptic cohort, and is reported in Hobson and Niemeyer (2013). 


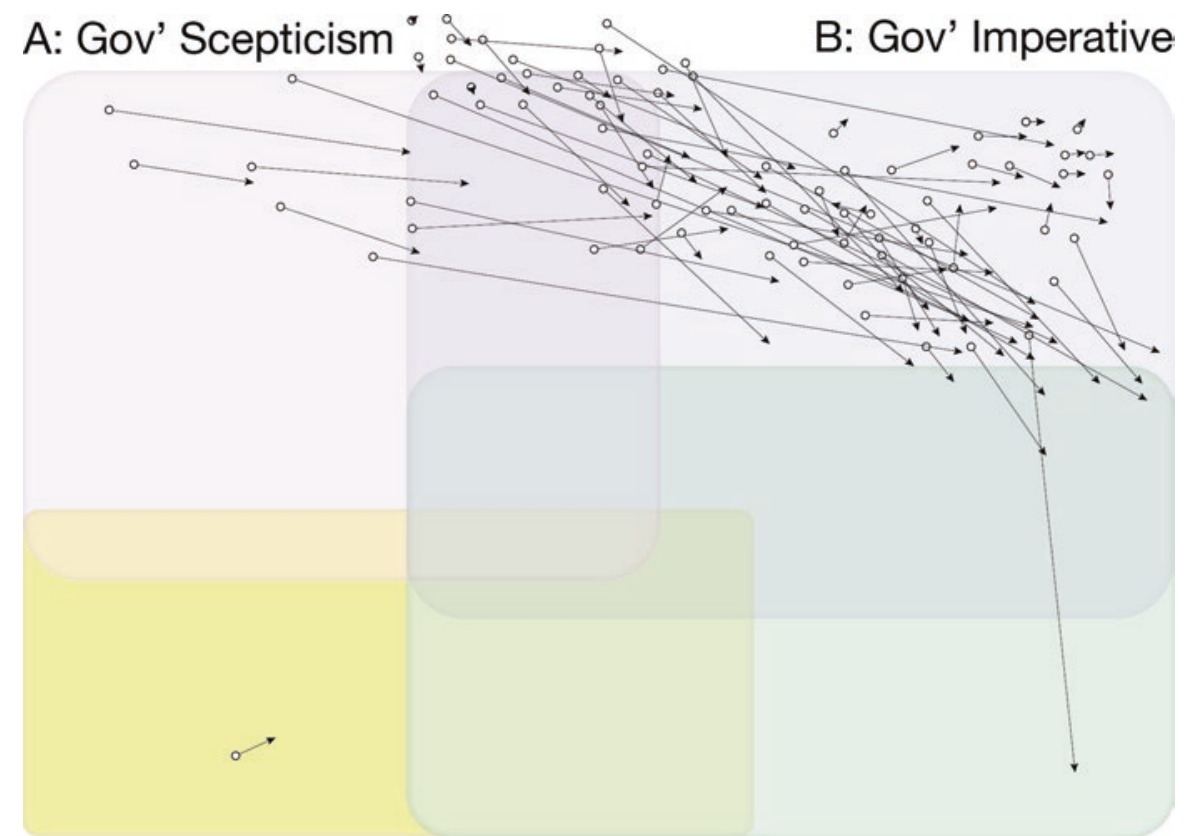

\section{C: Pragmatism}

Fig. 12.2 Migration across discourses: stages 1-2 (Baseline-High Emissions Scenario). Source: Design by author

arrows in Fig. 12.2, where the points at the beginning of each arrow reflect the baseline position of participants, prior to exposure to the climate change scenarios. ${ }^{5} \mathrm{At}$ the study's baseline stage, most participants could be located within Discourse B.

In Fig. 12.2, I capture the resulting movement across the discourse map from exposure to the climate change scenario. The scenario intervention induced a strong overall movement in the direction of Government Imperative (Discourse B), reflecting less an increase in reflexivity than a redirection from merely blaming government on the issue to demanding it take action. But it also involved a movement toward Alarmed Defeatism (D), which is an unreflexive perspective that represents a wholesale retreat from a desire to act on the issue (see Hobson \& Niemeyer, 2011). As anticipated, improved knowledge about climate change impacts thus did not appear to improve adaptive capacity and reflexivity.

As discussed above in relation to the Likert responses, the acquisition of knowledge about climate change had no lasting effect. Figure 12.3 shows the impact of the knowledge gains between Stages 1 and 2 following exposure to the climate change scenarios (lighter arrows with closed head) compared to the subsequent movement between Stages 2 and 3 in the follow-up prior to participation in the deliberative

\footnotetext{
${ }^{5}$ The deep climate sceptics who do not fit into this discourse schema are shown outside the map at a point reflecting those discourse they are most closely (but not significantly) associated with.
} 


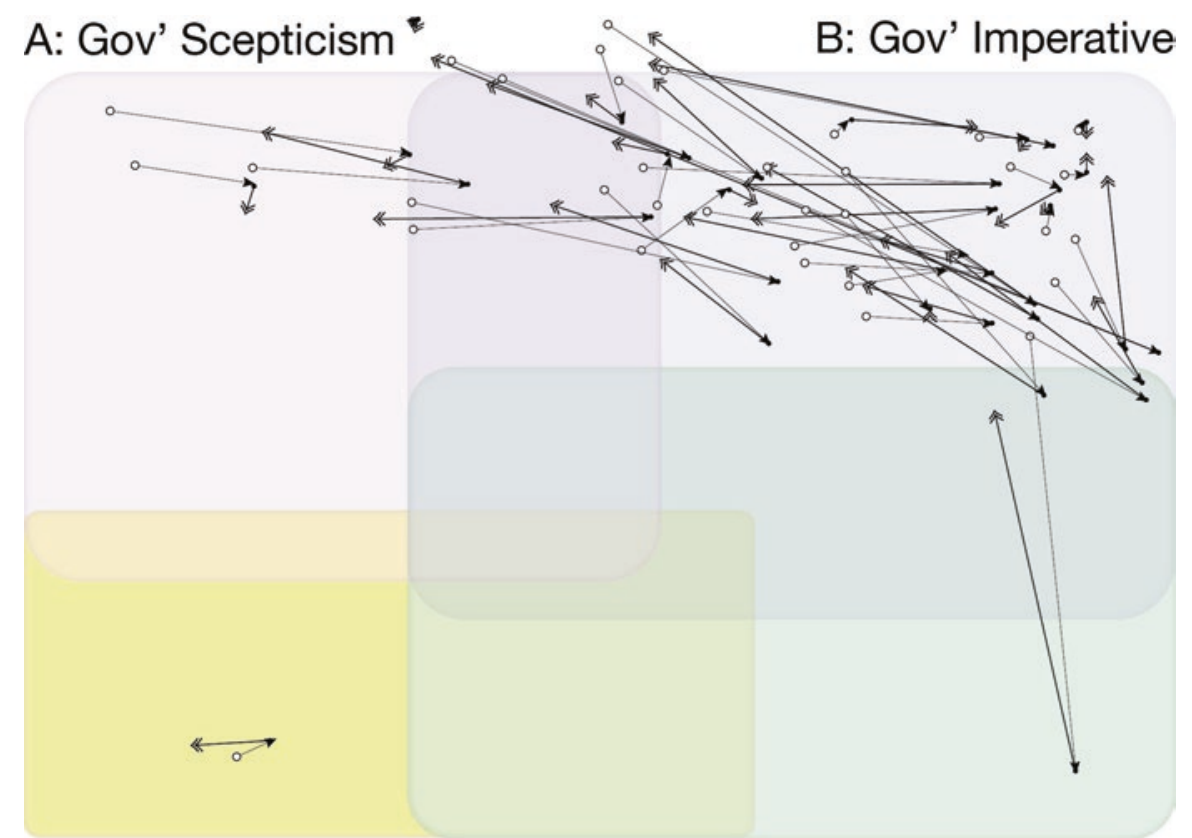

\section{C: Pragmatism}

Fig. 12.3 Migration across discourses: High Emissions Scenario Follow-Up. Source: Design by author

process (heavier arrows with open, double head). The figure reveals that most participants return to a position approaching their baseline after the initial impact of information. As is often the case for other studies, the effect of information alone is short lived (see Hobson \& Niemeyer, 2011; Howell, 2011).

Deliberation, on the other hand, had a very different impact—both quantitatively and qualitatively. The Likert response analysis in Table 12.1 indicates strong changes during deliberation, but looking at the changes through the lens of the discourses reveals the substantive story. The impact not only included a move across the existing discourse map; it involved a reconfiguration of the map itself and the way in which participants perceived possibilities for governance in relation to climate change. I schematically describe these post-deliberative discourses in Fig. 12.4 in the same manner as the scenario discourses in Fig. 12.2. They include:

A'. Accommodating Scepticism

$\mathrm{B}^{\prime}$. Governance and Engagement Imperative

E. Collective Action Imperative

F. Adaptive Reassurance

Overall, deliberative engagement increased the desire for more inclusive approaches to governance, rather than for outsourcing to government—observed in 


\section{A': Accommodating Scepticism B': Governance Imperative \\ $\mathrm{CC}$ is probably real \\ Distrust government \\ CC not quite \\ here yet \\ Not too late to act \\ $\mathrm{CC}$ is NOT depressing and out of control \\ Distrust media \\ Not simply climate variation \\ Need educational programmes \\ Trust Scientists \\ Good governance important \\ $\mathrm{CC}$ is a major issue \\ Need strong leadership \\ The market won't fix the problem \\ Australia is particularly vulnerable \\ There is enough evidence \\ Response wil be positive \\ Unilateral national action is valuable \\ Don't wait for leaders to act \\ F: Adaptive Reassurance E: Collective Action}

Fig. 12.4 Climate change Discourses: post-deliberation. Source: Design by author

respect to other deliberative processes (Niemeyer, Batalha, \& Dryzek, 2013), whose researchers commonly report increases in internal political efficacy (Morrell, 2005). This transformation is reflected in the change in nomenclature from "government" to "governance." Sceptics became more accommodationist in their perspective (Discourse A').

Following deliberation, most participants were ultimately located in the modified Discourse $\mathrm{A}^{\prime}$ or the new Discourse E (Collective Action), but the content of these new discourses is at least as important as the distribution of the participants. The overall post-deliberative discursive landscape represents greater adaptive possibilities compared to the other research stages (Hobson \& Niemeyer, 2011).

Of particular interest here is the relationship between knowledge and governance. With my analysis associated with Table 12.1, I have already alluded to a changing context in terms of beliefs about climate change, trust in knowledge sources, beliefs about governance capacity, and demand for changes to governance. I have summarized these features for both sets of discourses in Table 12.2 below, including the overall assessment of compatibility with creating the governance conditions for improved climate change adaptation as analyzed in Hobson and Niemeyer (2011).

In Table 12.2, I report the major features pertaining to governance, knowledge, and adaptation for the three main discourses in both discourse maps, as well as 


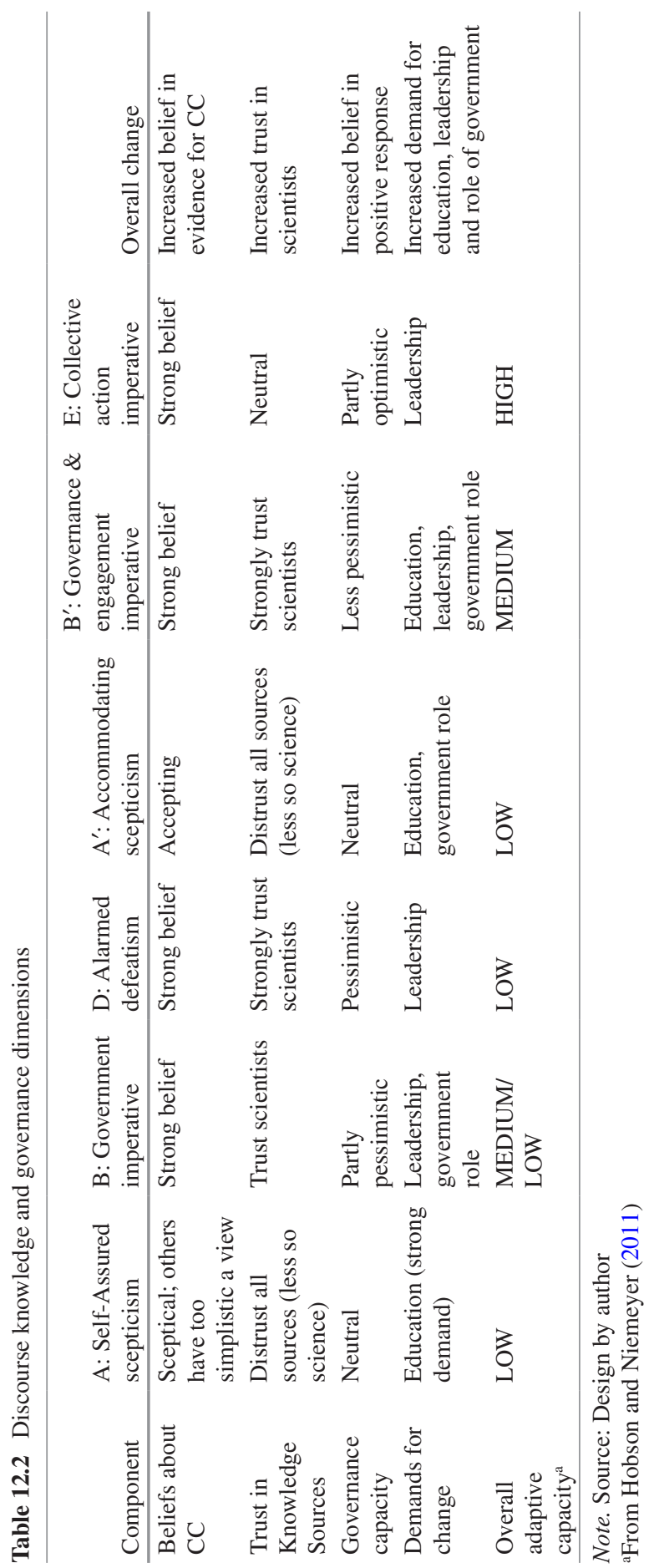


summarize the overall changes occurring during deliberation reported in Table 12.1. ${ }^{6}$ These must be assessed together because, although there is a significant overall change, the specific nature and source of the change varies between discourses. For example, the increased belief in evidence supporting climate change occurs mainly among the less entrenched sceptics associated with Discourse A, but they are less associated with the overall increase in trust in scientific sources of knowledge. That comes from participants associated with Discourses $\mathrm{A}^{\prime}$ and $\mathrm{B}^{\prime}$ - and erstwhile sceptics who migrated to Discourse A' during deliberation. Discourse A accounts for most of the observed overall change - in terms of increased belief in climate change, trust in scientists, belief in capacity for a positive response, and demand for education about climate change, increased leadership, and the role of government-by virtue of most participants associated with it post-deliberation. Particularly interesting is the emergence of Discourse E, which Hobson and Niemeyer (2011) associate with the strongest potential for adaptive climate governance. It represents an increase in the factors that contribute to improved collective action via increased acceptance of the reality of climate change and personal and collective efficacy in undertaking action-important factors contributing to the likelihood of increased action (Klöckner, 2013).

Overall, the findings point to deliberation contributing to substantial discursive transformation of the sort that is consistent with the kind of reflexivity demanded by the climate change issue. Researchers in another climate change adaptation and deliberation study, in this case conducted in Sydney, Australia, have also observed overall transformative dynamics very similar to those reported above (Schlosberg, Collins, \& Niemeyer, 2017).

\section{Knowledge, Reflexivity and Deliberative Systems}

With my findings in relation to the ACR case study, I illustrate the relationship between governance settings, knowledge uptake, and the potential behavioral response to climate change, which in turn feeds back into the governance context. Mere exposure to alternative knowledge or positions is not itself enough to induce reflection.

Worse, exposure to information in the absence of deliberation may actually be counterproductive if the response induces cognitive closure in the face of increasing dissonance via similar dynamics to those discussed earlier in respect to increasing issue complexity. The existence of high and in some cases increasing levels of climate scepticism owes some of its genesis to this phenomenon (Capstick et al., 2015).

A key factor influencing these dynamics is the citizens' disposition in their interaction with that knowledge. And that disposition is, in turn, influenced by the context. Accessing alternative arguments in a non-deliberative context-such as online

\footnotetext{
${ }^{6}$ I have omitted the fourth discourse for both maps for reasons of space. In both cases, the number of individuals associated with these discourses is very small and they do not constitute a major feature in the overall analysis.
} 
(Twitter), where the broader politics is characterized by hyper-partisanship (Bail et al., 2018) — can actually lead to a decline in openness to information. By contrast, changing that context to a more deliberative one induces a qualitatively different interaction with knowledge inputs, as evidenced by the ACR climate change case study.

To be sure, deliberation does not fundamentally change citizens, who still have roughly the same set of capabilities as before. But it serves to activate a set of capabilities-referred to earlier under the "deliberative stance" rubric—-that is otherwise not ordinarily activated in political settings. Part of this activation involves switching modes of cognition from shallow to deeper (see Niemeyer, 2011). But other kinds of activation also occur, consistent with the deliberative stance. The ideals of openness and intersubjectivity, valorized by deliberative democrats, stand in contrast to social psychological phenomena, such as cognitive closure (Kruglanski, 2013) and motivated reasoning (Taber \& Lodge, 2006).

The deliberative stance as described here implies a form of scepticism of the self: an acceptance that views may be incomplete or in need of updating. It is as much an affective disposition as a cognitive one, where high levels of anxiety can inhibit the processing of knowledge, particularly where it involves confronting implications and/or high levels of complexity. I observed this in the emergence of the Alarmed Defeatism discourse (D) in the ACR case study, which would likely undermine any effort to find collective solutions to the issue-with comparable effects observed elsewhere (e.g., Stoll-Kleemann, O'Riordan, \& Jaeger, 2001).

Another kind of anxiety can be observed in the form of deep climate sceptics, who usually hail from a demographic that feels threatened by structural changes necessary to meet the challenge, as well as holding certain (usually conservative) political values (Whitmarsh, 2011). As for the Twitter example (Bail et al., 2018) in the ACR case study, exposure to the climate change scenarios absent of deliberation sometimes entrenched existing views rather than transforming them (Hobson \& Niemeyer, 2013).

There are limits to this effect. Although participation in deliberation changed these dynamics for many of the sceptics, those most deeply sceptical opted instead to exit the process altogether (Hobson \& Niemeyer, 2013), demonstrating the limits to inducing self-scepticism and a deliberative stance for these groups. But, as I will discuss below, even these dynamics might be addressed to some extent if the issues of knowledge and environmental communication and inducing the deliberative stance were to be dealt with through a systemic lens.

\section{Systemic Deliberative Dynamics}

The findings so far reinforce the idea that the dynamics of environmental knowledge and behavior must be viewed as part of a wider governance context (Burgess, Harrison, \& Filius, 1998). But this is not to suggest that improving knowledge uptake (or in the case of climate change, acceptance) requires exclusive focus at the macro level. The effects must be understood in systemic terms-neither macro- nor micro-level, but rather operating at both levels as part of an overall systemic effect. Despite the onus on individual-level capacity in the form of the 
deliberative stance herein, exclusive focus on micro-level, individual knowledge dynamics at best is only likely to yield gains incommensurable to the challenge (Shove, 2010) and more of the same kind of linear modeling of environmental behavior that fails to escape the orbit of a knowledge deficit paradigm (O'Brien, 2012). Such an approach also reinforces the previous assertion regarding the incomplete nature of the impact science strategy advocated by reflexivity scholars, which fails to account for the processes that contribute to its uptake.

The nature of systems thinking required to address these shortcomings is informed by the nature of the dynamics observed above. The deliberative context of the ACR project impacted on the manner in which individuals interacted with the information provided. It reconfigured the citizens' orientation toward the knowledge system-accepting a division of labor in its production (Christiano, 2012)ameliorating the effects of the knowledge ignorance paradox (Ungar, 2000) as part of a changing discursive landscape. It also inured citizens to the forces of blandishment represented by anti-reflexive political forces and strategies of "merchants of doubt" (Oreskes \& Conway, 2010), something that researchers have observed in relation to a number of issues with similar knowledge dimensions (Niemeyer, 2011).

The key here is the changing discursive landscape within which individual capacities in the form of the deliberative stance were activated. An important contextual factor facilitating these changes is not just the mere fact of citizens deliberating, but the evolving language that was deployed as part of developing a shared understanding of the issue, which is partly captured by the discursive changes reported in Fig. 12.4.

These changes constitute systemic effects, even though for the ACR they are induced in fairly managed, micro-deliberative settings. Once the nature of these effects is understood, the challenge remains in terms of the mechanisms whereby they might be "scaled up" to a wider audience. There are possibilities, although much needs to be done to develop them (Niemeyer, 2014; Niemeyer \& Jennstål, 2018). Shove (2010), for example, advocates an approach to understanding human relationships with the environment through the lens of "practices" rather than behaviors, and a deepening of deliberative practices in a wider democratic context seems to fit well with this approach.

A democratic deepening of this sort yields potential systemic effects on the governance system, such as avoiding the climate change governance trap (Pidgeon, 2012) - as researchers observed in the Australian Capital Region climate change and governance study, it led to higher responsiveness at the individual and community level, as well as the demand for collective action. Such changes orient the system as a whole toward a high-order form of reflexivity (Dryzek \& Pickering, 2017), with improved trust in knowledge as well as a higher disposition toward translating that knowledge into action. The activation of a deliberative stance is neither a cause nor an effect of this shift, but an inherent component of an improved democratic practice.

To the extent that such practices can be scaled up, it is just possible that a polity that is more deliberative not only responds to climate change and the associated knowledge more constructively and in ways that reflect the inner desires of its 
citizens, but will also impact the anxious dynamics that induce citizens' anti-reflexive forces. These dynamics do not necessarily lead to increased knowledge on the part of citizens-although there is good evidence that this would also be the case (Andersen \& Hansen, 2007; Grönlund, Setälä, \& Herne, 2010; Luskin, Fishkin, \& Jowell, 2002) — but they do appear to hold a good deal of promise in addressing the pathologies of knowledge that characterize much of the climate change debate and policy response in the prevailing governance context.

\section{Conclusion}

That knowledge alone is insufficient to ensure action on complex and challenging governance issues such as climate change is demonstrable on both normative and empirical grounds. Here, I have attempted to demonstrate the manner in which the context plays a role in this process from the perspective of deliberative governance, particularly in respect to the discursive landscape that frames the modes in which knowledge may be accepted, rejected, or simply ignored. This discursive context includes the changing climate itself, which has the power to alter the discursive landscape and, paradoxically, work against the operation of reflexivity in governance systems.

Deliberation works on a small scale, by activating capacities that exist in most citizens but are not activated in prevailing governance settings. These capacities, captured by the concept of the deliberative stance, include a more normatively appealing scepticism of the self and a willingness to judiciously consider and absorb new information. This does not demand complete comprehension, because a deliberative system is based on trust that distributes knowledge generation and synthesis.

Building capacity to capture these dynamics beyond the mini-public could involve reforming public engagement informed by deliberative principles in ways that scale up these effects. And these reforms could involve harnessing the power of mini-publics, to the extent that they can be articulated with the wider governance system (Niemeyer \& Jennstål, 2018). A good deal of work remains to be done on such approaches and their effectiveness.

In spite of these gaps, in this chapter I have demonstrated the utility of conceptualizing knowledge uptake through the lens of governance. The adoption of systems thinking beyond micro-level information deficit approaches or macropolitical strategies is also of relevance. A discursively understood system of governance cannot separate the citizen from the governance context, and it is here that productive solutions might be found.

\section{Appendix}

Table 12.3 shows the statements used in the Q sort for the CCPS case study, along with the $z$-scores representing the typical level of agreement/disagreement for each statement associated with each of the discourses. 


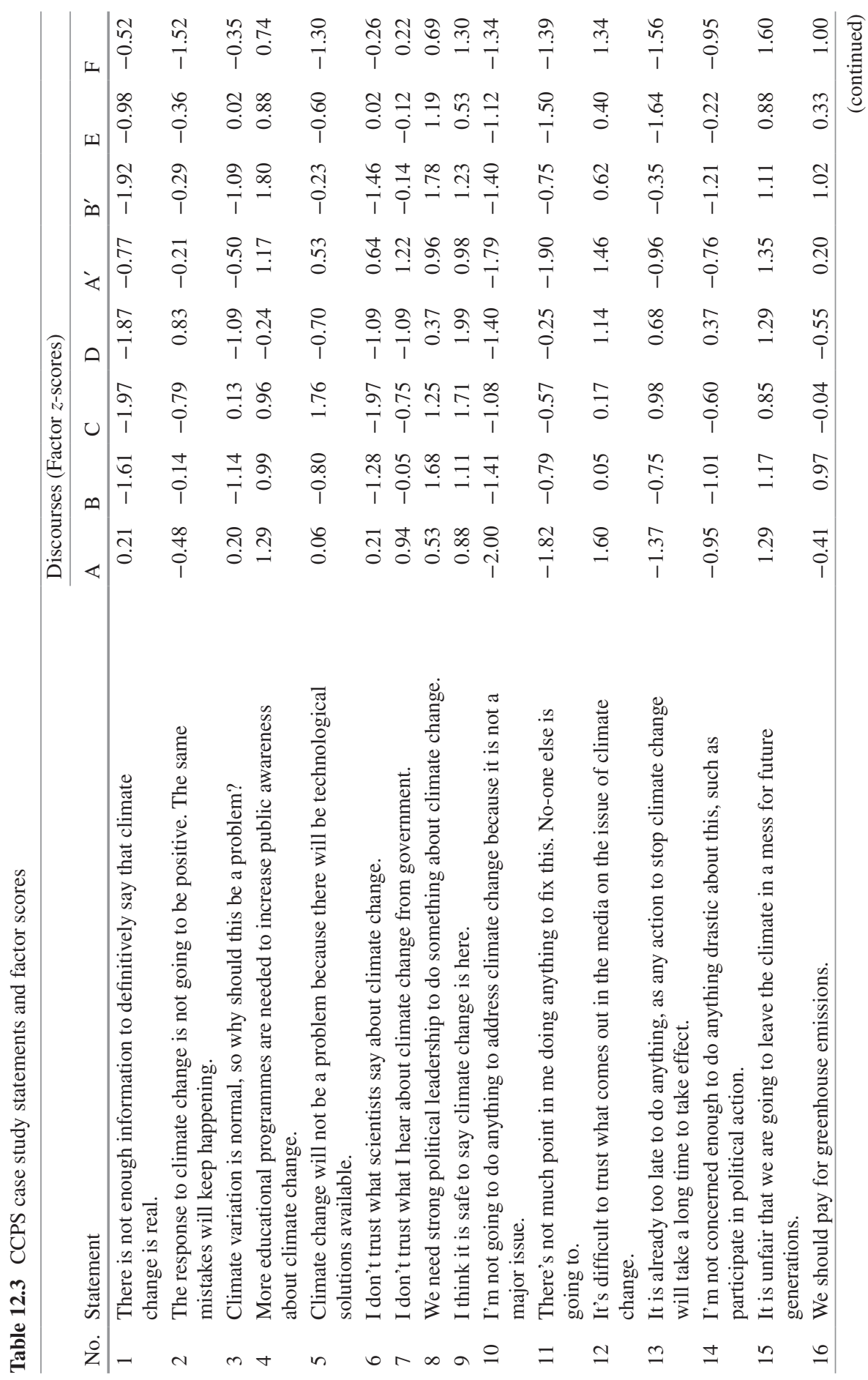




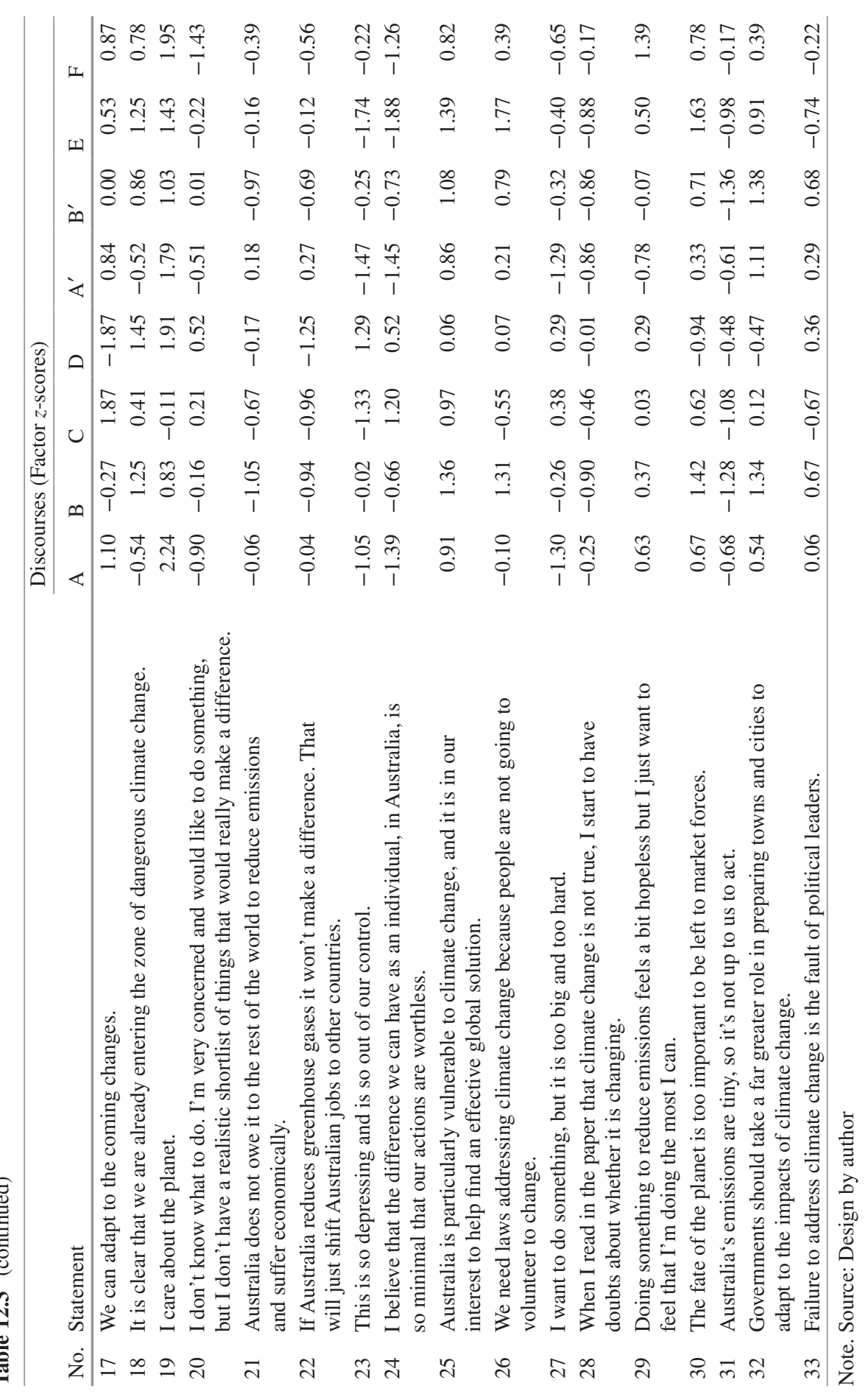




\section{References}

Andersen, V. N., \& Hansen, K. M. (2007). How deliberation makes better citizens: The Danish deliberative poll on the euro. European Journal of Political Research, 46, 531-556. https://doi. org/10.1111/j.1475-6765.2007.00699.x

Bächtiger, A., Niemeyer, S., Neblo, M., Steenbergen, M. R., \& Steiner, J. (2010). Disentangling diversity in deliberative democracy: Competing theories, their blind spots and complementarities. Journal of Political Philosophy, 18, 32-63. https://doi. org/10.1111/j.1467-9760.2009.00342.x

Bail, C., Argyle, L., Brown, T., Bumpus, J., Chen, H., Fallin Hunzaker, M. B., Lee, J., Mann, M., Merhout, F., \& Volfovsky, A. (2018). Exposure to opposing views can increase political polarization: Evidence from a large-scale field experiment on social media. https://doi.org/10.17605/ OSF.IO/4YGUX

Beck, U. (1992). Risk society: Towards a new modernity. London: SAGE.

Bord, R. J., O'Connor, R. E., \& Fischer, A. (2000). In what sense does the public need to understand global climate change? Public Understanding of Science, 9, 205-218. https://doi. org/10.1088/0963-6625/9/3/301

Brown, S. R. (1980). Political subjectivity: Applications of $Q$ methodology in political science. New Haven, CT: Yale University Press.

Burgess, J., Harrison, C. M., \& Filius, P. (1998). Environmental communication and the cultural politics of environmental citizenship. Environment and Planning A: Economy and Space, 30, 1445-1460. https://doi.org/10.1068/a301445

Capstick, S., Whitmarsh, L., Poortinga, W., Pidgeon, N., \& Upham, P. (2015). International trends in public perceptions of climate change over the past quarter century. Wiley Interdisciplinary Reviews: Climate Change, 6, 35-61. https://doi.org/10.1002/wcc.321

Carlton, J. S., Perry-Hill, R., Huber, M., \& Prokopy, L. S. (2015). The climate change consensus extends beyond climate scientists. Environmental Research Letters, 10, 094025. https://doi. org/10.1088/1748-9326/10/9/094025

Chambers, S. (2012). Deliberation and mass democracy. In J. Parkinson \& J. J. Mansbridge (Eds.), Deliberative systems: Deliberative democracy at the large scale (pp. 52-71). New York, NY: Cambridge University Press.

Christiano, T. (2012). Deliberation among experts and citizens. In J. Parkinson \& J. J. Mansbridge (Eds.), Deliberative systems: Deliberative democracy at the large scale (pp. 27-51). NewYork, NY: Cambridge University Press.

Christoff, P. (2013). Climate discourse complexes, national climate regimes and Australian climate policy. Australian Journal of Politics \& History, 59, 349-367. https://doi.org/10.1111/ ajph. 12020

Cohen, J. (2007). Deliberative democracy. In S. W. Rosenberg (Ed.), Deliberation, participation and democracy: Can the people govern? (pp. 219-236). Basingstoke: Palgrave Macmillan.

Curato, N., \& Niemeyer, S. J. (2013). Reaching out to overcome political apathy: Building participatory capacity through deliberative engagement. Politics \& Policy, 41, 355-383. https://doi. org/10.1111/polp.12015

Curato, N., Niemeyer, S. J., \& Dryzek, J. S. (2013). Appreciative and contestatory inquiry in deliberative forums: Can group hugs be dangerous? Critical Policy Studies, 7, 1-17. https://doi. org/10.1080/19460171.2012.758595

Danielson, S. B. (2015). Q method as discourse analysis: Three cautionary tales. Retrieved from http://debitage.net/academic/Qdiscourse-webdraft.pdf

Dryzek, J. S. (1990). Discursive democracy: Politics, policy, and political science. Cambridge, UK: Cambridge University Press.

Dryzek, J. S. (2009). Democratization as deliberative capacity building. Comparative Political Studies, 42, 1379-1402. https://doi.org/10.1177/0010414009332129

Dryzek, J. S., \& Niemeyer, S. J. (2008). Discursive representation. American Political Science Review, 102, 481-494. https://doi.org/10.1017/S0003055408080325 
Dryzek, J. S., \& Pickering, J. (2017). Deliberation as a catalyst for reflexive environmental governance. Ecological Economics, 131, 353-360. https://doi.org/10.1016/j.ecolecon.2016.09.011

Dunlap, R. E. (2013). Climate change skepticism and denial: An introduction. American Behavioral Scientist, 57, 691-698. https://doi.org/10.1177/0002764213477097

Grönlund, K., Setälä, M., \& Herne, K. (2010). Deliberation and civic virtue: Lessons from a citizen deliberation experiment. European Political Science Review, 2, 95-117. https://doi. org/10.1017/S1755773909990245

Habermas, J. (2006). Political communication in media society: Does democracy still enjoy an epistemic dimension? The impact of normative theory on empirical research. Communication Theory, 16, 411-426. https://doi.org/10.1111/j.1468-2885.2006.00280.x

Hobson, K. P., \& Niemeyer, S. J. (2011). Public responses to climate change: The role of deliberation in building capacity for adaptive action. Global Environmental Change, 21, 957-971. https://doi.org/10.1016/j.gloenvcha.2011.05.001

Hobson, K. P., \& Niemeyer, S. J. (2013). "What sceptics believe": The effects of information and deliberation on climate change scepticism. Public Understanding of Science, 22, 396-412. https://doi.org/10.1177/0963662511430459

Howell, R. A. (2011). Lights, camera ... action? Altered attitudes and behaviour in response to the climate change film "The Age of Stupid." Global Environmental Change, 21, 177-187. https:// doi.org/10.1016/j.gloenvcha.2010.09.004

Jennstål, J. (2018). Deliberative participation and personality: The effect of traits, situations and motivation. European Political Science Review, 10, 417-440. https://doi.org/10.1017/ S1755773918000024

Klöckner, C. A. (2013). A comprehensive model of the psychology of environmental behaviour: A meta-analysis. Global Environmental Change, 23, 1028-1038. https://doi.org/10.1016/j. gloenvcha.2013.05.014

Kruglanski, A. W. (2013). The psychology of closed mindedness. Essays in Social Psychology: Vol. 1. London: Taylor and Francis. https://doi.org/10.4324/9780203506967

Kruglanski, A. W., \& Boyatzi, L. M. (2012). The psychology of closed and open mindedness, rationality, and democracy. Critical Review, 24, 217-232. https://doi.org/10.1080/0891381 1.2012 .711023

Kruglanski, A. W., \& Webster, D. M. (1996). Motivated closing of the mind: "Seizing" and "Freezing." Psychological Review, 103, 263-283.https://doi.org/10.1037/0033-295X.103.2.263

Luskin, R. C., Fishkin, J. S., \& Jowell, R. (2002). Considered opinions: Deliberative polling in Britain. British Journal of Political Science, 32, 455-487. https://doi.org/10.1017/ S0007123402000194

McCright, A. M., \& Dunlap, R. E. (2010). Anti-reflexivity. Theory, Culture \& Society, 27, 100-133. https://doi.org/10.1177/0263276409356001

McCright, A. M., Dunlap, R. E., \& Marquart-Pyatt, S. T. (2016). Political ideology and views about climate change in the European Union. Environmental Politics, 25, 338-358. https://doi. org/10.1080/09644016.2015.1090371

Morrell, M. E. (2005). Deliberation, democratic decision-making and internal political efficacy. Political Behavior, 27, 49-69. https://doi.org/10.1007/s11109-005-3076-7

Morrell, M. E. (2010). Empathy and democracy: Feeling, thinking, and deliberation. University Park, PA: Pennsylvania State University Press. https://doi.org/10.5325/j.ctt7v16x

Năkićenović, N., Alcamo, J., Davis, G., de Vries, B., Fenhann, J., Gaffin, S., Gregory, K., Grübler, A., Jung, T. Y., Kram, T., La Rovere, E. L., Michaelis, L., Mori, S., Morita, T., Pepper, W., Pitcher, H., Price, L., Riahi, K., Roehrl, A., Rogner, H.-H., Sankovski, A., Schlesinger, M., Shukla, P., Smith, S., Swart, R., van Rooijen, S., Victor, N., \& Dadi, Z. (2000). Emissions scenarios: Special report on emission scenarios: A special report of working group iii of the Intergovernmental Panel on Climate Change. Cambridge, UK: Cambridge University Press.

Niemeyer, S. J. (2011). The emancipatory effect of deliberation: Empirical lessons from minipublics. Politics \& Society, 39, 103-140. https://doi.org/10.1177/0032329210395000 
Niemeyer, S. J. (2014). Scaling up deliberation to mass publics: Harnessing mini-publics in a deliberative system. In K. Grönlund, A. Bächtiger, \& M. Setälä (Eds.), Deliberative minipublics: Involving citizens in the democratic process (pp. 177-202). Essex: ECPR.

Niemeyer, S. J. (2019). Analysis of deliberative transformation: A multi-level approach incorporating Q methodology. In S. Elstub \& O. Escobar (Eds.), Handbook of democratic innovation and governance (pp. 540-557). Cheltenham: Edward Elgar. https://doi. org/10.4337/9781786433862.00049

Niemeyer, S. J., Batalha, L., \& Dryzek, J. S. (2013). Changing orientations toward Australian democracy. In L. Carson, J. Gastil, J. Hartz-Karp, \& R. Lubensky (Eds.), The Australian citizens' parliament and the future of deliberative democracy (pp. 133-145). University Park, PA: Pennsylvania State University Press.

Niemeyer, S. J., \& Jennstål, J. (2018). Scaling up deliberative effects: Applying lessons of minipublics. In A. Bächtiger, J. S. Dryzek, M. E. Warren, \& J. J. Mansbridge (Eds.), Handbook of deliberative democracy (pp. 329-347). Oxford, UK: Oxford University Press.

O’Brien, K. (2012). Global environmental change iii: Closing the gap between knowledge and action. Progress in Human Geography, 37, 587-596. https://doi.org/10.1177/0309132512469589

Oreskes, N. (2018). The scientific consensus on climate change: How do we know we're not wrong? In E. A. Lloyd \& E. Winsberg (Eds.), Climate modelling: Philosophical and conceptual issues (pp. 31-64). Cham: Springer International.

Oreskes, N., \& Conway, E. M. (2010). Merchants of doubt: How a handful of scientists obscured the truth on issues from tobacco smoke to global warming (1st U.S. edition). New York: Bloomsbury.

Owen, D., \& Smith, G. (2015). Survey article: Deliberation, democracy, and the systemic turn. Journal of Political Philosophy, 23, 213-234. https://doi.org/10.1111/jopp.12054

Pidgeon, N. (2012). Public understanding of, and attitudes to, climate change: UK and international perspectives and policy. Climate Policy, 12, 85-106. https://doi.org/10.1080/1469306 2.2012.702982

Pierce, J. C., Lovrich, N. P., \& Dalton, R. J. (2000). Contextual influences on environmental knowledge: Public familiarity with technical terms in nuclear weapons production in Russia and the United States. Environment and Behavior, 32, 188-208. https://doi. org/10.1177/00139160021972496

Scott, M. (2020). Knowledge of governance as knowledge for governance: Spatialized techniques of neutralization. In J. Glückler, G. Herrigel, \& M. Handke (Eds.), Knowledge for governance (pp. 51-67). Knowledge and Space: Vol. 15. Cham: Springer.

Schlosberg, D., Collins, L. B., \& Niemeyer, S. J. (2017). Adaptation policy and community discourse: Risk, vulnerability, and just transformation. Environmental Politics, 26, 413-437. https://doi.org/10.1080/09644016.2017.1287628

Shove, E. (2010). Beyond the ABC: Climate change policy and theories of social change. Environment and Planning A: Economy and Space, 42, 1273-1285. https://doi. org/10.1068/a42282

Stevenson, H., \& Dryzek, J. S. (2012). The discursive democratisation of global climate governance. Environmental Politics, 21, 189-210. https://doi.org/10.1080/09644016.2012.651898

Stoll-Kleemann, S., O’Riordan, T., \& Jaeger, C. C. (2001). The psychology of denial concerning climate mitigation measures: Evidence from Swiss focus groups. Global Environmental Change, 11, 107-117. https://doi.org/10.1016/S0959-3780(00)00061-3

Taber, C. S., \& Lodge, M. (2006). Motivated skepticism in the evaluation of political beliefs. American Journal of Political Science, 50, 755-769. https://doi. org/10.1111/j.1540-5907.2006.00214.x

Ungar, S. (2000). Knowledge, ignorance and the popular culture: Climate change versus the ozone hole. Public Understanding of Science, 9, 297-312. https://doi.org/10.1088/0963-6625/9/3/306 
van der Linden, S. L., Leiserowitz, A. A., Feinberg, G. D., \& Maibach, E. W. (2015). The scientific consensus on climate change as a gateway belief: Experimental evidence. PLoS One, 10, 1-8. https://doi.org/10.1371/journal.pone.0118489

Whitmarsh, L. (2011). Scepticism and uncertainty about climate change: Dimensions, determinants and change over time. Global Environmental Change, 21, 690-700. https://doi.org/10.1016/j. gloenvcha.2011.01.016

Open Access This chapter is licensed under the terms of the Creative Commons Attribution 4.0 International License (http://creativecommons.org/licenses/by/4.0/), which permits use, sharing, adaptation, distribution and reproduction in any medium or format, as long as you give appropriate credit to the original author(s) and the source, provide a link to the Creative Commons license and indicate if changes were made.

The images or other third party material in this chapter are included in the chapter's Creative Commons license, unless indicated otherwise in a credit line to the material. If material is not included in the chapter's Creative Commons license and your intended use is not permitted by statutory regulation or exceeds the permitted use, you will need to obtain permission directly from the copyright holder. 